\title{
RELATOS DE PESQUISAS \\ DIAGNÓSTICO DA GESTÃO DO CONHECIMENTO NO SETOR PÚBLICO: ESTUDO DE CASO NO CORPO DE BOMBEIROS MILITAR DE ALAGOAS
}

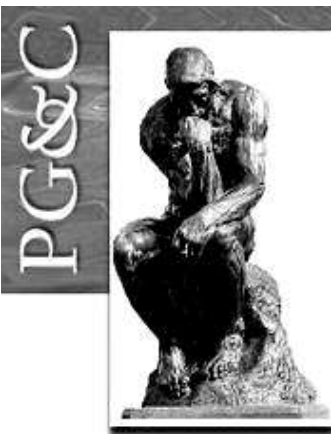

\author{
Luiz Augusto de Medeiros Lira \\ Mestre em Administração Pública pela Universidade Federal de Alagoas, \\ Brasil. Oficial do Corpo de Bombeiros Militar de Alagoas, Brasil. \\ E-mail: luizaugusto.lira@bombeiros.al.gov.br \\ Ibsen Mateus Bittencourt Santana Pinto \\ Doutor em Administração de Empresas pela Universidade Mackenzie, \\ Brasil. Professor da Universidade Federal de Alagoas, Brasil. \\ E-mail: ibsen.ead@gmail.com
}

\begin{abstract}
Resumo
A Gestão do Conhecimento (GC) se mostra como alternativa para as organizações públicas, auxiliando-as no enfrentamento dos desafios da era do conhecimento. Seu conjunto de práticas e abordagens colabora para o aprimoramento dos processos, produtos e serviços prestados à sociedade, manifestando-se através da inovação e da aprendizagem continuada. A presente pesquisa teve por objetivo diagnosticar o grau de maturidade em GC do Corpo de Bombeiros Militar de Alagoas (CBMAL), identificando pontos fortes e oportunidades de melhoria. Para tanto, utilizou-se do instrumento de avaliação que integra o Modelo de Gestão do Conhecimento para a Administração Pública Brasileira (MGCAPB). O diagnóstico do grau de maturidade em GC do CBMAL ratificou a hipótese da pesquisa, no que tange ao estágio inicial da GC na corporação, evidenciando uma lacuna de desenvolvimento até o mais elevado nível de maturidade em GC, que corresponde à institucionalização. Ademais, este processo de autoavaliação colaborou na identificação de pontos fortes e oportunidades de melhoria da GC na organização, dando base para a consolidação das demais etapas do processo de institucionalização. A contribuição acadêmica do presente estudo se atesta pela originalidade da abordagem conferida ao tema em uma organização bombeiro militar, que poderá ser estendida a instituições de natureza similar, nas áreas de defesa e segurança pública do Brasil e do exterior. Trata-se de uma aplicação prática do MGCAPB, reafirmando sua viabilidade e colaborando para o retrato do atual estado do setor público brasileiro em termos de GC. Inicia o processo de institucionalização, ao cumprir a etapa de diagnóstico.
\end{abstract}

Palavras-chave: Gestão do Conhecimento. Grau de maturidade. Setor Público. Organizações militares. Corpo de Bombeiros.

\section{DIAGNOSIS OF KNOWLEDGE MANAGEMENT IN THE PUBLIC SECTOR: CASE STUDY IN THE ALAGOAS MILITARY FIRE AND RESCUE SERVICE}

\begin{abstract}
Knowledge Management (KM) is an alternative for public organizations, helping them to face the challenges of the knowledge era. Its set of practices and approaches collaborates to improve the processes, products and services rendered to society, manifesting itself through innovation and continued learning. This research aimed to diagnose the maturity level in Knowledge Management of the Alagoas Military Fire and Rescue Service, identifying strengths and opportunities for improvement. Therefore, we used the assessment instrument that integrates the Knowledge Management Model for the Brazilian Public Administration. The diagnosis of the maturity level in KM confirmed the research hypothesis, with regard to the initial stage of KM in the corporation, evidencing a development gap up to
\end{abstract}

Perspectivas em Gestão \& Conhecimento, João Pessoa, v. 11, número especial, p. 35-55, mar. 2021.

DOI: http://dx.doi.org/10.22478/ufpb.2236-417X.2021v11nEspecial.57574

http://periodicos.ufpb.br/ojs2/index.php/pgc. ISSN: 2236-417X. Publicação sob Licença (cc) EY-NC-ND 
the highest level of maturity in KM, which corresponds to institutionalization. In addition, this selfassessment process helped to identify strengths and opportunities for improving KM in the organization, providing the basis for consolidating the other steps of the institutionalization process. The academic contribution of the present study is attested by the originality of the approach given to the theme in a military organization, which may be extended to institutions of a similar nature, in the areas of defense and public security in Brazil and abroad. It is a practical application of the theoretical model used, reaffirming its viability and contributing to present of the current state of the brazilian public sector in terms of KM. Starts the institutionalization process, when completing the diagnostic stage.

Keywords: Knowledge management. Maturity level. Public sector. Military organizations. Fire and Rescue Service.

\section{INTRODUÇÃO}

As constantes mudanças no cenário político-econômico-social têm levado as organizações a dirigirem esforços em torno de temas como aprendizagem e inovação, buscando otimizar o uso do melhor conhecimento disponível (BATISTA, 2016). Neste sentido, a Gestão do Conhecimento se mostra como modelo adequado para o enfrentamento de ambientes incertos, dinâmicos e complexos, não se limitando ao setor privado, dada a sua aplicabilidade, também, nas mais diversas áreas da administração pública (ANGELIS, 2011; MCADAM; REID, 2000).

Por outro lado, são reportados vários desafios à implementação satisfatória da GC na administração pública: cultura organizacional e resistência às mudanças de rotinas e procedimentos (SVEIBY; SIMONS, 2002); alternância política e rotatividade de pessoal (CARILLO, 2016); além da natureza burocrática e hierárquica das organizações (ANGELIS, 2015). Outro fator relevante, segundo Paixão (2004), diz respeito à falta de institucionalização da GC, sendo muitas vezes desenvolvida por iniciativas isoladas, em resposta a demandas momentâneas. Para Batista (2012), a institucionalização representa o maior nível de maturidade de GC a ser alcançado por uma organização, em uma escala que contempla os seguintes estágios: 1) Reação; 2) Iniciação; 3) Introdução; 4) Refinamento; e 5) Maturidade.

Ainda segundo Batista (2015), o grau de maturidade em GC está intimamente relacionado aos resultados obtidos, sendo mais expressivos à medida que se aproxima do estágio de institucionalização. Para o autor, tal condição é diretamente dependente do apoio e da formalização estratégica da GC, que deve ser norteada por uma política institucional (BATISTA, 2015). Marques et al. (2019) corroboram com tal apontamento, ao afirmarem que o comprometimento organizacional influencia na transferência de conhecimento, refletindo no seu grau de maturidade.

Para Massaro, Dumay e Garlatti (2015), a despeito da elevada importância do conhecimento em áreas essenciais, como nas forças armadas, polícia, corpo de bombeiros e serviços de emergências, há poucos estudos de GC em torno desse rol de instituições. Tal apontamento se reforça pela criticidade do conhecimento na atividade finalística destas organizações, onde um eventual erro poderá repercutir num custo imensurável, resultando, em último nível, na perda de vidas humanas.

Em um estudo de caso realizado em torno da experiência das comunidades de prática do CBMAL, Lira e Lemos (2017) afirmaram se tratar de uma iniciativa isolada na área de GC, dentre outras possivelmente existentes, que deveriam ser inventariadas e integradas estrategicamente na instituição. Por sua vez, ao explorarem as perspectivas do tema para a corporação, Lira e Pinto (2018) ratificaram tal constatação, percebendo uma realidade que pouco diverge da maior parte das organizações públicas do Brasil em termos de GC: apesar da existência de práticas esporádicas, a falta de institucionalização é um entrave para o

Perspectivas em Gestão \& Conhecimento, João Pessoa, v. 11, número especial, p. 35-55, mar. 2021. 
aproveitamento pleno das potencialidades da GC, cujos resultados são diretamente relacionados ao seu grau de formalização estratégica pela organização (BATISTA, 2015).

Neste sentido, no intuito de subsidiar o processo de institucionalização da GC no âmbito da corporação, a presente pesquisa teve por objetivo diagnosticar o grau de maturidade em GC do CBMAL, identificando pontos fortes e oportunidades de melhoria. Para tanto, toma por base o instrumento de avaliação que integra o Modelo de Gestão do Conhecimento para a Administração Pública Brasileira (MGCAPB), proposto por Batista (2012).

Além desta seção introdutória, a presente pesquisa está estruturada em um referencial teórico, sucedido pelas considerações metodológicas. Em seguida, procede a análise e discussão dos resultados, tendo seu fechamento realizado pelas considerações finais.

\section{REFERENCIAL TEÓRICO}

\subsection{Gestão do Conhecimento no Setor Público}

De disciplina emergente no final do século passado (IVES, TORREY; GORDON, 1998) para um campo do saber consolidado na atualidade, a Gestão do Conhecimento cada vez mais se apresenta como alternativa viável para a otimização do desempenho de organizações públicas ou privadas (MCADAM; REID, 2000). Para Wiig (1997), o objetivo da GC reside em maximizar a eficácia relacionada ao conhecimento da empresa, fazendo-a agir de maneira inteligente, garantindo sua viabilidade e sucesso. Tal apontamento corrobora com Dalkir (2005), que reconhece a GC como uma atividade de coordenação de pessoal, tecnologia, processos e estrutura organizacional, manifestada pela criação, compartilhamento e aplicação do conhecimento, a fim de promover a aprendizagem contínua na organização.

O capital intelectual, segundo Wiig (2002), é um recurso elementar para a definição do curso das ações governamentais e, na sua ausência, elas serão baseadas na ignorância e na falta de compreensão, dando-se de forma arbitrária e ineficiente. Neste sentido, o trabalho da administração pública - complexo e importante por natureza - pode ser otimizado pelas novas possibilidades advindas da Gestão do Conhecimento (WIIG, 2002).

Em um trabalho que se dispôs a mapear tendências em termos de princípios e diretrizes na gestão pública, Cavalcante (2017) se debruça em torno dos principais movimentos e reformas apontados pela literatura: a burocracia tradicional; o movimento gerencialista, influenciado pelo New Public Management (NPM); e a era contemporânea, do pós-NPM, marcada pela governança pública. Dentre seus apontamentos, o autor se refere à importância da implementação de melhorias pequenas e constantes nos processos e serviços públicos (micro-improvements), ao invés de se optar por reformas amplas e custosas, que se mostram impraticáveis em sua totalidade (CAVALCANTE, 2017). Nesse viés, a GC se apresenta como alternativa viável, alinhada às tendências do pós-NPM, à medida que incorpora um conjunto de modernas práticas de gestão, capazes de otimizar o desempenho das instituições, além de potencializar a participação cidadã e o controle social, colaborando para a governança compartilhada (ANGELIS, 2015).

Segundo Schlesinger et al. (2008), para o setor público, a GC possui uma finalidade mais ampla, transcendendo o objetivo de aumentar o desempenho organizacional. Segundo Batista (2012), isto se reflete dada a sua influência fora dos muros das instituições, impactando, em último nível, até no desenvolvimento da sociedade.

Há vasta literatura sobre os benefícios da GC para o setor público, dentre os quais podem ser elencados: auxilia na formulação da estratégia das organizações (TAKEUCHI, 2013); evita a repetição de erros (DALKIR, 2005); oferece suporte à tomada de decisão (LAIHONEN E MÄNTYLÄ, 2018); aumenta a capacidade de inovação (AGUNE et al., 2014); contribui para a

Perspectivas em Gestão \& Conhecimento, João Pessoa, v. 11, número especial, p. 35-55, mar. 2021. 
formulação, implementação e avaliação de políticas, programas e projetos públicos (ANGELIS, 2015); promove a melhoria dos processos internos e das competências essenciais da organização, além de aumentar a eficiência, a qualidade e a efetividade social dos serviços prestados à população (BATISTA, 2012).

Face às considerações até então apresentadas, espera-se que o emprego da GC na administração pública seja cada vez mais difundido dentre as instituições, sobretudo nos países em desenvolvimento. Neste sentido, na subseção seguinte, será delineado um panorama da GC no setor público brasileiro, onde se percebe uma clara lacuna para a sua consolidação, o que endossa a proposição de medidas nessa área de gestão

\subsection{Panorama atual da Gestão do Conhecimento no Setor Público Brasileiro}

Batista et al. (2005) analisaram a situação da GC em dois grupos de organizações federais: 1) Vinte e oito órgãos da administração direta, dentre eles vários ministérios e as forças armadas; e 2) Seis empresas estatais: Banco do Brasil, Serviço Federal de Processamento de Dados, Caixa Econômica Federal, Petrobrás, Correios e Eletrosul. No que diz respeito ao estágio de implantação das práticas de GC no primeiro grupo, o estudo identificou um número reduzido de iniciativas implantadas. No segundo grupo, por sua vez, ficou evidente uma maior disseminação e aproveitamento das práticas de GC. De uma forma geral, notam-se resultados ainda tímidos, resultantes de esforços pulverizados, em torno de um tema ainda desconhecido pela alta administração e carente de uma política ampla para sua institucionalização (BATISTA et al., 2005).

Passados dez anos do trabalho de Batista et al. (2005), uma nova pesquisa foi realizada (BATISTA, 2015), dessa vez ainda mais abrangente, contando com a participação de 81 organizações do Executivo, Legislativo e Judiciário federal e do Ministério Público, além do Tribunal de Contas da União (TCU) e do Operador Nacional do Sistema Elétrico (ONS). Da análise da situação atual da externalização e formalização da GC destas instituições, Batista (2015) reconhece progressos dentre aquelas que se encontram nos estágios intermediário e avançado. Todavia, o autor relata preocupação sobre o fato da maior parte das organizações ainda se encontrarem no estágio inicial de externalização e formalização da GC. Além disso, em uma segunda via deste mesmo estudo, comparam-se os resultados atuais com aqueles obtidos na pesquisa inicial, constatando que o panorama pouco se alterou neste período em meio às instituições participantes, não havendo avanços significativos. Por outro lado, o autor reporta a existência de uma relação evidente entre o apoio e a formalização estratégica da GC e os resultados obtidos (BATISTA, 2015).

A tentativa de instituir uma Política de Gestão do Conhecimento para a Administração Pública Federal (PGC/APF) é relatada por Fresneda e Gonçalves (2007) como fruto do engajamento do Comitê Técnico de Gestão do Conhecimento e Informação Estratégica (CTGCIE), no âmbito do Comitê Executivo do Governo Eletrônico (CEGE). A formulação da proposta tomou por base o panorama delineado nos estudos de Batista (2004 e 2005). No entanto, apesar dos esforços do CT-GCIE, a PGC/APF não chegou a ser implementada (BATISTA, 2015) e, em 2016, o trabalho foi descontinuado por força do Decreto no 8.638 (BRASIL, 2016), que institui a Política de Governança Digital e causa a extinção do CEGE.

Desse modo, apesar de ser considerada como uma das principais medidas para a institucionalização da GC no âmbito da administração pública federal (BATISTA et al., 2005), a falta de uma política pública que determine a adoção da GC nos órgãos federais ainda se mostra como uma lacuna estratégica relevante (BATISTA, 2015).

No âmbito dos estados, há registros da implementação de políticas públicas de GC em pelos menos três unidades da federação. Em São Paulo, a iniciativa se deu por meio do Decreto no 53.963 (SÃO PAULO, 2009), que institui a Política de Gestão do Conhecimento e

Perspectivas em Gestão \& Conhecimento, João Pessoa, v. 11, número especial, p. 35-55, mar. 2021. 
Inovação. Em Minas Gerais, a Política Estadual de Gestão do Conhecimento é regulamentada pela Resolução SEPLAG/MG no 55 (SEPLAG, 2012), que se desdobrou em um Plano Estadual de Gestão do Conhecimento (BATISTA et al., 2015). Já em Rondônia, a formalização da política estadual se deu mediante o Decreto no 22.660 (RONDÔNIA, 2018), cuja gestão é atribuída a um comitê estadual designado para tal fim.

Tanto em Minas Gerais quanto em Rondônia, a formulação e implementação da Política Estadual de GC é baseada no Modelo de Gestão do Conhecimento para a Administração Pública Brasileira (MGCAPB), publicado pelo Instituto de Pesquisa Econômica Aplicada (IPEA) e de autoria do Prof. Dr. Fábio Ferreira Batista, que será adotado no presente trabalho e cuja descrição se dará a seguir.

\subsection{Modelo de Gestão do Conhecimento para a Administração Pública Brasileira}

Resultante do trabalho de Batista (2012), o MGCAPB se caracteriza como "um modelo de GC genérico, holístico, com foco em resultados e específico para a administração pública brasileira, com a finalidade de orientar as organizações públicas na implementação da GC $^{\prime \prime}$ (BATISTA, 2012, p. 13). O autor se baseou na premissa de que, apesar da pluralidade de modelos de GC na literatura, cuja maioria deles é voltada para o setor privado, as organizações públicas devem adotar um modelo especificamente voltado para o segmento, dado o seu contexto particular. Representado na Figura 1, o MGCAPB e seus principais componentes são esclarecidos em seguida.

Figura 1 - MGCAPB e seus componentes

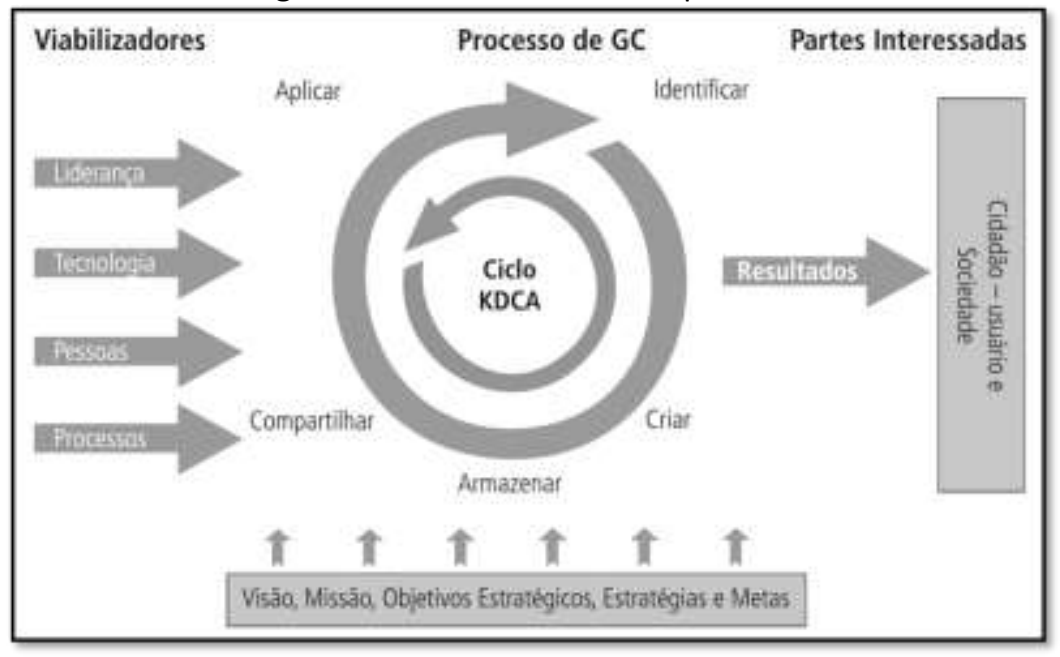

Fonte: Batista (2012)

O primeiro componente do MGCAPB diz respeito ao alinhamento da estratégia de GC aos direcionadores estratégicos da organização: visão de futuro, missão institucional, objetivos estratégicos e metas (BATISTA, 2012). Trata-se do fundamento básico do modelo, destacando que a GC não deve ser vista como um fim em si mesmo, mas como um meio para alcançar os objetivos estratégicos da instituição (BATISTA et al., 2015).

O segundo componente do modelo, segundo Batista (2012), são os fatores críticos de sucesso ou viabilizadores da GC, a saber: 1) Liderança; 2) Tecnologia; 3) Pessoas; 4) Processos. Cada um deles exerce papel importante na institucionalização da GC na organização.

O terceiro componente corresponde ao processo de GC, composto pelas seguintes atividades: identificar, criar, armazenar, compartilhar e aplicar conhecimento (BATISTA, 2012).

Perspectivas em Gestão \& Conhecimento, João Pessoa, v. 11, número especial, p. 35-55, mar. 2021. 
O quarto componente do MGCAPB é o ciclo KDCA, uma variação do ciclo PDCA (Plan, Do, Check, Act) voltada para a GC, pois à medida que substitui o " $\mathrm{P}$ " pelo " $\mathrm{K}$ " evidencia o foco do planejamento no conhecimento (BATISTA, 2012). Para o autor, o ciclo KDCA deve ser utilizado na gestão de processos, projetos, programas e políticas públicas, como forma de otimizar a eficiência, a qualidade e a efetividade da administração pública.

O quinto componente do modelo são os resultados da GC, categorizados por Batista (2012) como imediatos e finais. A aprendizagem (individual e organizacional) e a inovação (produtos, serviços, processos, práticas, tecnologias e políticas públicas) são tidos como resultados imediatos. Em último nível, o aumento da eficiência, a melhoria da qualidade e da efetividade social, a observância aos princípios constitucionais da administração pública e a promoção do desenvolvimento são os resultados finais da GC (BATISTA, 2012).

Finalmente, o sexto componente do MGCAPB são as partes interessadas na administração pública, ou seja, o cidadão-usuário e a sociedade (BATISTA, 2012). O primeiro, seja ele pessoa física ou jurídica, é o destinatário final do serviço público e, para o autor, deve fazer parte do foco da estratégia de GC nas instituições. Por sua vez, a sociedade está sujeita aos reflexos da intervenção do setor público, devendo ter seus anseios contemplados por meio de temas como desenvolvimento, ética, responsabilidade socioambiental, transparência e participação social.

A metodologia de implementação do Plano de Gestão do Conhecimento (PGC), com base no MGCAPB, é composta por quatro etapas e 20 atividades, resumidas no Quadro 1, apresentado a seguir.

Quadro 1 - Metodologia de implementação do Plano de Gestão do Conhecimento

\begin{tabular}{|l|l|}
\hline \multicolumn{2}{|l|}{ Etapa 1 - Diagnosticar } \\
\hline 01 & Realizar a autoavaliação \\
\hline 02 & Elaborar o business case para justificar a importância da GC \\
\hline 03 & Definir a visão de GC \\
\hline 04 & Definir os objetivos de GC \\
\hline 05 & Definir as estratégias de GC \\
\hline 06 & $\begin{array}{l}\text { Identificar e priorizar os projetos de GC a serem implementados (individual, em equipe, } \\
\text { intraorganizacional e interorganizacional) }\end{array}$ \\
\hline 07 & Definir a estrutura de governança de GC: comitê estratégico, unidade central e equipes de GC \\
\hline 08 & Definir as práticas de GC \\
\hline 09 & Elaborar plano de sensibilização das pessoas na organização \\
\hline 10 & Elaborar o Plano de Gestão do Conhecimento \\
\hline \multicolumn{2}{|l|}{ Etapa 3 - Desenvolver } \\
\hline 11 & Escolher e implementar um projeto-piloto \\
\hline 12 & Avaliar o resultado do projeto-piloto \\
\hline 13 & Utilizar as lições aprendidas para implementar o projeto em toda a organização \\
\hline \multicolumn{2}{|}{} \\
\hline 14 & Discutir os fatores de sucesso na implementação da GC \\
\hline 15 & Definir meios para manter os resultados obtidos com a implementação da GC \\
\hline 16 & Definir maneiras de lidar com a resistência à implementação da GC \\
\hline 17 & Elaborar o plano de comunicação do PGC \\
\hline 18 & Definir estratégia de avaliação contínua na implementação do PGC \\
\hline 19 & Implementar o plano de sensibilização, o plano de comunicação e o PGC \\
\hline 20 & Monitorar e avaliar continuamente o Plano de Gestão do Conhecimento \\
\hline
\end{tabular}

A escolha do MGCAPB como base para o presente trabalho se justifica por se tratar de um modelo genérico (concebido para qualquer organização pública), holístico (permite uma

Perspectivas em Gestão \& Conhecimento, João Pessoa, v. 11, número especial, p. 35-55, mar. 2021. 
visão integral da $\mathrm{GC}$ ), com foco em resultados e específico para o setor público brasileiro (BATISTA, 2012). Tal justificativa se reforça dada à aplicação prática do modelo em várias organizações públicas desde a sua concepção (BATISTA et al., 2014; BATISTA et al., 2015).

O diagnóstico da GC no CBMAL, objeto do presente trabalho, está estruturado em torno do instrumento de avaliação que integra o MGCAPB, dando-se em obediência à metodologia apresentada na seção seguinte.

\section{METODOLOGIA}

No Quadro 1, constam as etapas necessárias para a elaboração do PGC de uma organização. Consoante aos objetivos da pesquisa, foram realizados os procedimentos atinentes à etapa de diagnóstico, em particular, a autoavaliação.

Segundo Batista (2012), o instrumento para avaliação da GC na Administração Pública é o meio utilizado para realizar a autoavaliação do grau de maturidade de GC da organização, tendo por objetivos: 1) Determinar o grau de utilização da GC na organização pública; 2) Determinar se a organização pública conta com condições adequadas para implementar e manter de forma sistemática os processos de GC; 3) Identificar os pontos fortes e as oportunidades de melhoria da GC.

Tomando por base os preceitos do MGCAPB, discutido na seção anterior, o instrumento para avaliação da GC se utiliza dos seguintes critérios: 1.0) Liderança em GC; 2.0) Processo; 3.0) Pessoas; 4.0) Tecnologia; 5.0) Processos de GC; 6.0) Aprendizagem e inovação; e 7.0) Resultados da GC. A análise de cada um destes 7 critérios é composta por 6 assertivas, totalizando 42 itens (questões), que constam no Anexo I. Para cada item, é atribuída a pontuação de 1 a 5, com base em uma das escalas transcritas no Quadro 2.

Quadro 2 - Escalas de pontuação do instrumento de avaliação da GC

\begin{tabular}{|c|c|}
\hline \multirow{2}{*}{\multicolumn{2}{|c|}{$\begin{array}{c}\text { Escala } 1 \\
\text { Utilizada nos itens de } 1 \text { a } 36 \text { dos critérios de } 1 \text { a } 6 \text { e nos itens } 37 \text { e } 38 \text { do critério } 7\end{array}$}} \\
\hline & \\
\hline Pontos & $\begin{array}{c}\text { Significado } \\
\end{array}$ \\
\hline 1 & As ações descritas são muito mal realizadas ou ainda não são realizadas. \\
\hline 2 & As ações descritas são mal realizadas. \\
\hline 3 & As ações descritas são realizadas de forma adequada. \\
\hline 4 & As ações descritas são bem realizadas. \\
\hline 5 & As ações descritas são muito bem realizadas. \\
\hline \multicolumn{2}{|r|}{ Escala 2} \\
\hline \multicolumn{2}{|r|}{ Utilizada no critério 7: resultados. Itens de 39 a 42} \\
\hline Pontos & Significado \\
\hline 1 & $\begin{array}{l}\text { A organização não melhorou ou ainda não é possível comprovar melhorias } \\
\text { por ausência de indicadores. }\end{array}$ \\
\hline 2 & Houve melhoria nos resultados de alguns indicadores utilizados. \\
\hline 3 & Houve melhoria nos resultados da maioria dos indicadores utilizados. \\
\hline 4 & Houve melhoria em quase todos os indicadores utilizados. \\
\hline 5 & Houve melhoria em todos os indicadores utilizados. \\
\hline
\end{tabular}

Fonte: Adaptado de Batista (2012)

A aplicação do instrumento deve envolver grupos de pessoas, aferindo-se a pontuação individual e a pontuação em grupo. Após isso, deve-se registrar os pontos fortes e oportunidades de melhoria para cada um dos sete critérios, os quais devem ser resumidos e priorizados, utilizando-se, para tanto, da Matriz dos Pontos Fortes e Oportunidades de Melhoria da GC. Por fim, a pontuação de cada grupo é inserida na Tabela Resumo com a Pontuação dos Grupos. A pontuação da organização em cada critério é obtida pela média

Perspectivas em Gestão \& Conhecimento, João Pessoa, v. 11, número especial, p. 35-55, mar. 2021. 
aritmética da pontuação dos grupos, podendo ser representada em um gráfico radar, que permite a comparação entre a pontuação obtida e a pontuação máxima.

A pontuação final, que determinará o grau de maturidade em GC da organização, é resultante da soma da pontuação média em todos os critérios, variando de 42 a 210 pontos, uma vez que o limite inferior corresponde a 1 vez o número de questões (42), enquanto que o mais alto é de 5 vezes esta quantidade (210). Conforme se percebe na Figura 2, a depender da pontuação, a organização é enquadrada em um dos cinco níveis de maturidade de GC.

Figura 2 - Níveis de maturidade em GC

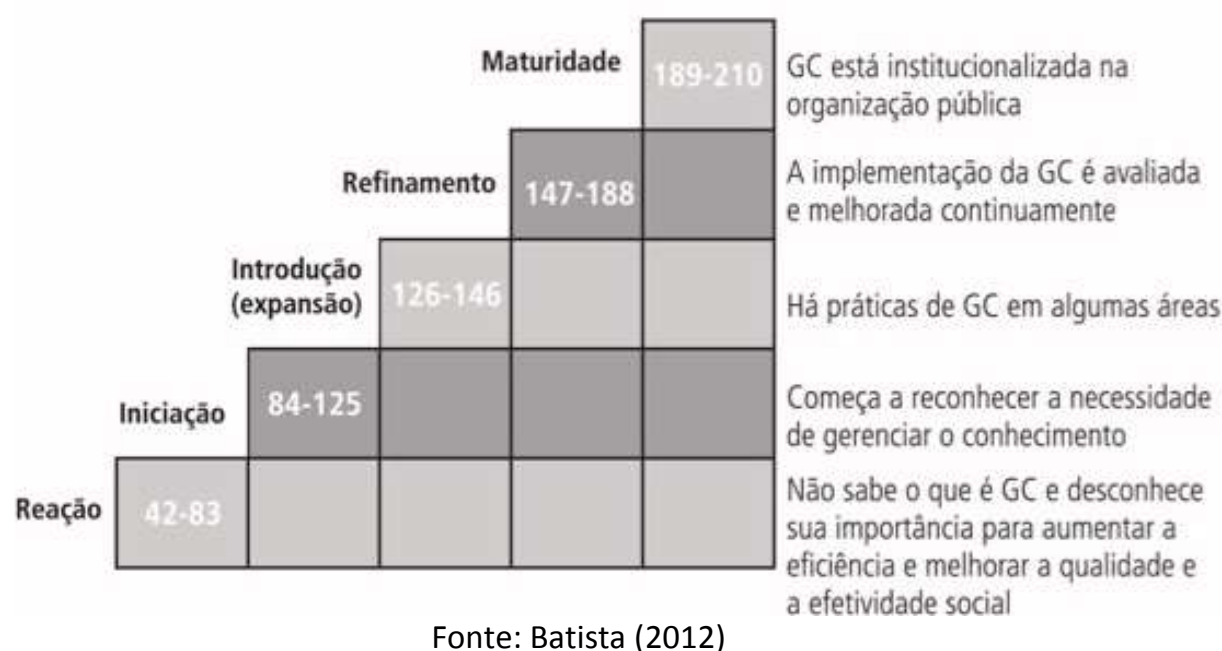

Na organização em análise, a aplicação do instrumento se deu por ocasião da I Oficina de Gestão do Conhecimento do Corpo de Bombeiros Militar de Alagoas. Na oportunidade, foram apresentados conceitos básicos de GC e sua aplicabilidade para o CBMAL, de maneira a sensibilizar o público-alvo quanto à importância do tema para a instituição, além de situá-los no contexto do presente trabalho. Também foram explicados os objetivos da pesquisa e os formulários que integram o instrumento para a avaliação da GC na Administração Pública. Os participantes foram orientados quanto ao preenchimento, sendo os resultados utilizados para a autoavaliação do grau de maturidade de GC da organização.

A seleção dos participantes da oficina se deu em observância à recomendação do Manual de Implementação da GC na Administração Pública, anexo ao trabalho de Batista (2012), que aponta para a necessidade de se identificarem pessoas com afinidade ao assunto em análise. Neste sentido, optou-se pela formação de grupos de maneira a contemplar os setores responsáveis pela gestão, em nível tático e estratégico, dos elementos tidos como viabilizadores do MGCAPB: 1) Liderança; 2) Tecnologia; 3) Pessoas; 4) Processos. Os 22 participantes foram reunidos em cinco grupos, especificados no Quadro 3, sendo o público composto por oficiais intermediários e superiores do quadro combatente.

Quadro 3 - Descrição dos grupos de participantes da oficina

\begin{tabular}{|c|c|c|}
\hline \multirow{2}{*}{ Grupo } & Setores & $\begin{array}{c}\text { No de } \\
\text { pessoas }\end{array}$ \\
\hline \multirow{2}{*}{1} & Comando Geral & \multirow{2}{*}{4} \\
\hline \multirow{3}{*}{2} & Subcomando Geral & \\
\cline { 2 - 2 } & Assessoria de Planejamento (ASSPLAN) & \multirow{2}{*}{4} \\
\cline { 2 - 3 } & $\begin{array}{c}\text { Superintendência de Planejamento, Orçamento, Finanças e Contabilidade } \\
\text { (SPOFC) }\end{array}$ & \\
\hline
\end{tabular}

Perspectivas em Gestão \& Conhecimento, João Pessoa, v. 11, número especial, p. 35-55, mar. 2021. 


\begin{tabular}{|c|c|c|}
\hline \multirow{3}{*}{3} & Superintendência de Tecnologia da Informação e Comunicação (STIC) & \multirow{3}{*}{5} \\
\hline & Superintendência de Atividades Técnicas (SAT) & \\
\hline & Superintendência de Material e Patrimônio (SMP) & \\
\hline \multirow{2}{*}{4} & Superintendência de Valorização de Pessoas (SVP) & \multirow{2}{*}{4} \\
\hline & Superintendência de Ensino e Pesquisa (SEP) & \\
\hline \multirow{3}{*}{5} & Comando Operacional da Região Metropolitana (CORM) & \multirow{3}{*}{5} \\
\hline & Comando Operacional do Interior (COI) & \\
\hline & Ajudância Geral & \\
\hline
\end{tabular}

Fonte: Autoria própria

\section{RESULTADOS}

\subsection{Perfil institucional do Corpo de Bombeiros Militar de Alagoas}

Fundado em 1947, o CBMAL teve sua origem vinculada à Polícia Militar de Alagoas, da qual se emancipou em 1993 (CBMAL, 2019a). Hoje, compõe a administração direta do governo estadual como uma instituição autônoma, sendo subordinada à Secretaria de Estado da Segurança Pública (ALAGOAS, 2015). Nos termos constitucionais, é considerado como força auxiliar e reserva do Exército Brasileiro (BRASIL, 1988), tendo seu funcionamento regido pelos preceitos de uma organização militar.

A corporação é responsável pelo atendimento em todo o território estadual, dispondo de 13 postos de bombeiros, instalados em 9 dos 102 municípios alagoanos, sendo cinco na capital e os demais no interior (CBMAL, 2019b). Isto significa que, necessariamente, a área de atuação das unidades extrapola os limites da cidade onde se encontra sediada.

Dentre as unidades operacionais, quatro delas desempenham atividade especializada nas áreas de Combate a Incêndio, Busca e Salvamento, Salvamento Aquático e Atendimento Pré-hospitalar, todas sediadas na capital. As demais funcionam como unidades multiemprego, exercendo suas funções operacionais em mais de uma área de atuação.

Sua organização, funcionamento e atribuições são reguladas, em linhas gerais, pela Constituição Federal, Constituição Estadual e pela Lei de Organização Básica. Além disso, sujeita-se à Lei Delegada no 047/2015, instituída pelo atual governo estadual, que reestrutura a corporação e seus setores (ALAGOAS, 2015).

No Brasil, o Corpo de Bombeiros Militar faz parte do rol de instituições de Segurança Pública, em conformidade com o art. 144 da Constituição da República, segundo o qual, além das atribuições definidas em Lei, cabe às corporações à execução de atividades de Defesa Civil (BRASIL, 1988). Em Alagoas, a Lei Estadual no 7.444, de 28 de dezembro de 2012 (ALAGOAS, 2012), estabelece as demais competências institucionais, sob o escopo da missão institucional de "preservar a vida, o patrimônio e o meio ambiente" (CBMAL, 2020).

Do nível estratégico às unidades operacionais, sua estrutura organizacional abarca setores diversificados, conforme se percebe no organograma trazido pela Figura 3.

Perspectivas em Gestão \& Conhecimento, João Pessoa, v. 11, número especial, p. 35-55, mar. 2021. 
Figura 3 - Organograma resumido do CBMAL

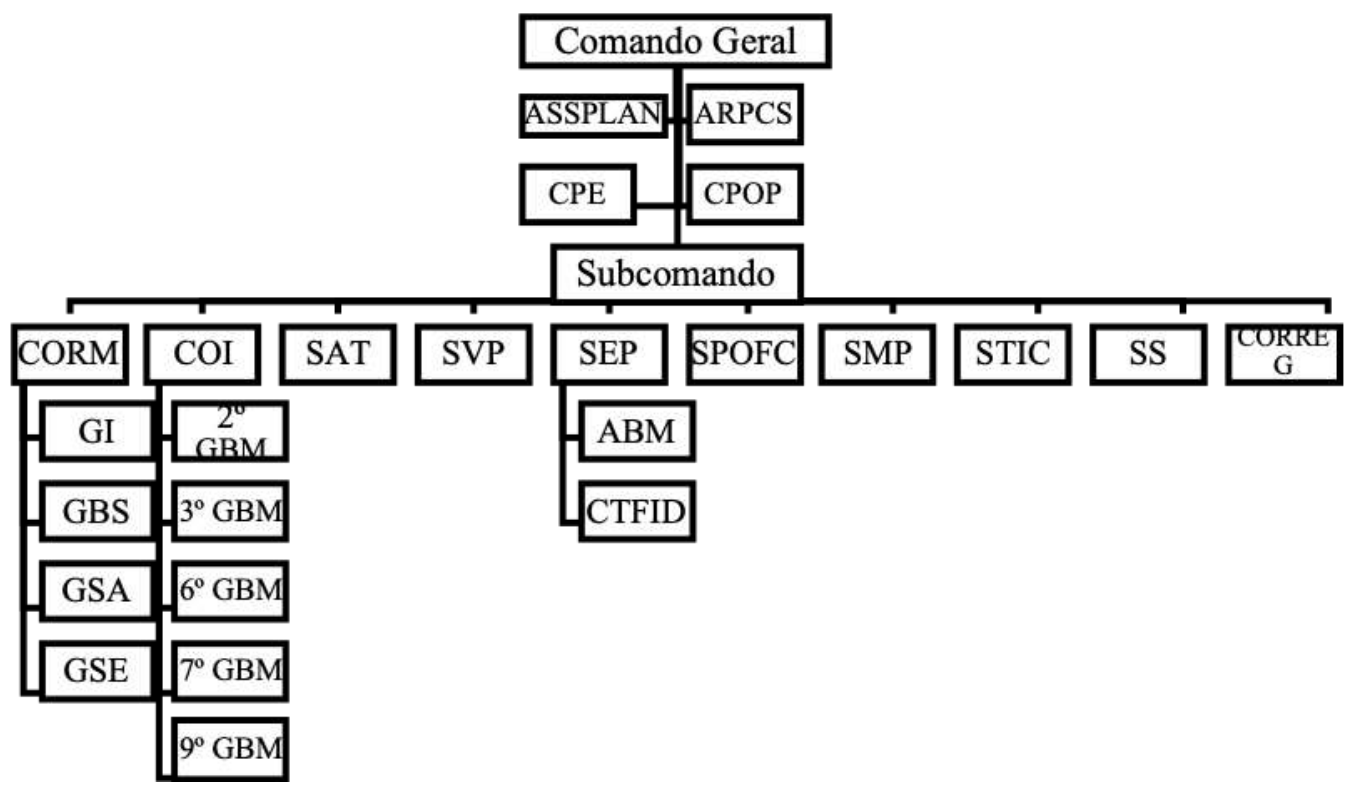

Fonte: Adaptado de Alagoas (2015)

\subsection{Grau de maturidade da Gestão do Conhecimento no CBMAL}

O diagnóstico do grau de maturidade em GC do CBMAL foi obtido mediante a aplicação do Instrumento de Avaliação da GC na Administração Pública proposto por Batista (2012), nos moldes descritos na seção de metodologia. Na Tabela 1, é apresentado um resumo da pontuação atribuída pelos grupos participantes da pesquisa em cada um dos sete critérios de avaliação, resultando na pontuação global de 87,41.

Tabela 1 - Resumo da pontuação dos grupos

\begin{tabular}{c|c|c|c|c|c|c|c|c}
\multicolumn{8}{c}{ Tabela 1 - Resumo da pontuação dos grupos } \\
\hline Critérios & $\mathbf{1 . 0}$ & $\mathbf{2 . 0}$ & $\mathbf{3 . 0}$ & $\mathbf{4 . 0}$ & $\mathbf{5 . 0}$ & $\mathbf{6 . 0}$ & $\mathbf{7 . 0}$ & $\begin{array}{c}\text { Pontuação } \\
\text { máxima }\end{array}$ \\
\hline Pontuação & $\mathbf{3 0}$ & $\mathbf{3 0}$ & $\mathbf{3 0}$ & $\mathbf{3 0}$ & $\mathbf{3 0}$ & $\mathbf{3 0}$ & $\mathbf{3 0}$ & $\mathbf{2 1 0}$ \\
\hline Grupo 1 & 10,25 & 12,25 & 12,75 & 21,00 & 10,00 & 13,00 & 9,25 & 88,50 \\
\hline Grupo 2 & 11,00 & 13,00 & 11,50 & 17,75 & 11,25 & 15,75 & 9,25 & 89,50 \\
\hline Grupo 3 & 10,40 & 10,00 & 10,20 & 18,60 & 9,60 & 13,40 & 7,00 & 79,20 \\
\hline Grupo 4 & 12,00 & 12,25 & 12,50 & 18,50 & 10,00 & 14,75 & 9,25 & 89,25 \\
\hline Grupo 5 & 11,40 & 12,80 & 11,20 & 20,80 & 11,60 & 13,80 & 9,00 & 90,60 \\
\hline Pontuação Total (PT) & 55,05 & 60,30 & 58,15 & 96,65 & 52,45 & 70,70 & 43,75 & 437,05 \\
\hline $\begin{array}{c}\text { Pontuação Média } \\
\text { (PT/5) }\end{array}$ & $\mathbf{1 1 , 0 1}$ & $\mathbf{1 2 , 0 6}$ & $\mathbf{1 1 , 6 3}$ & $\mathbf{1 9 , 3 3}$ & $\mathbf{1 0 , 4 9}$ & $\mathbf{1 4 , 1 4}$ & $\mathbf{8 , 7 5}$ & $\mathbf{8 7 , 4 1}$ \\
\hline Colocação & $\mathbf{5 0}$ & 30 & 40 & 10 & $\mathbf{6 0}$ & $\mathbf{2 0}$ & $\mathbf{7 0}$ & - \\
\hline
\end{tabular}

Fonte: Elaborado pelos autores

Identificou-se, portanto, que o estágio em que a corporação se encontra é o de "iniciação", o segundo de uma escala de cinco níveis, apresentada na Figura 2, o que significa que a organização "começa a reconhecer a necessidade de gerenciar o conhecimento". O Gráfico 1 apresenta a pontuação obtida por critério de avaliação da GC, comparando-a com a pontuação máxima possível (30 pontos), evidenciando uma lacuna entre a atual situação da GC

Perspectivas em Gestão \& Conhecimento, João Pessoa, v. 11, número especial, p. 35-55, mar. 2021. 
na organização e o maior nível de maturidade segundo o MGCAPB, onde a GC estaria institucionalizada.

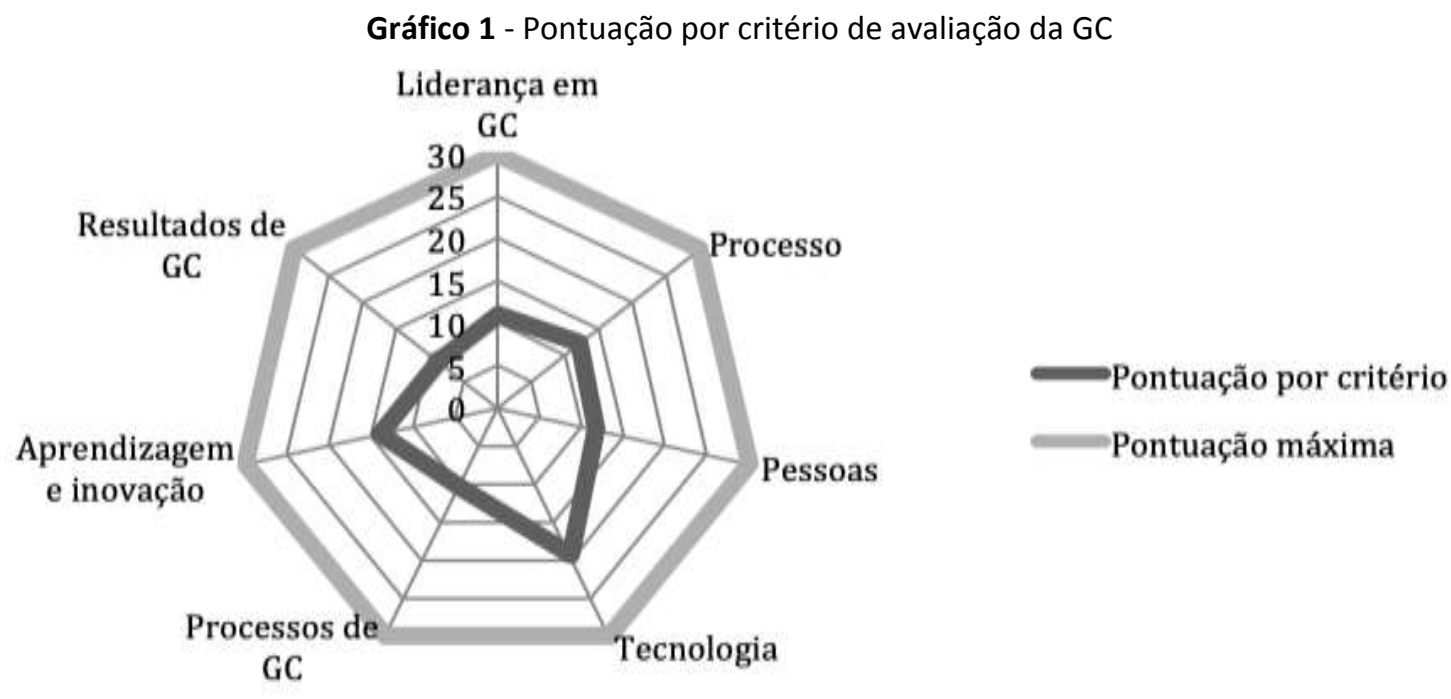

Fonte: Elaborado pelos autores

Observam-se as maiores lacunas nos critérios de "resultados de $\mathrm{GC}^{\text {", }}$, seguido pelos "processos de GC", "liderança em GC", "pessoas" e "processo". Por outro lado, os critérios mais bem avaliados foram "tecnologia" e "aprendizagem e inovação", o que coaduna com o atual panorama institucional em GC, resultando de seus pontos fortes e oportunidades de melhoria, discutidos a seguir.

No que diz respeito à tecnologia, a pontuação reflete o trabalho realizado pela Superintendência de Tecnologia da Informação e Comunicação, sobretudo no que tange ao portfólio de sistemas informatizados da corporação, que possui um elevado potencial de aplicabilidade para fins de GC. Além disso, o emprego da intranet como principal meio de compartilhamento de informações é fruto do empenho da Assessoria de Relações Públicas e Comunicação Social, subsidiada pelos demais setores da organização, na produção e difusão de conteúdos de forma continuada.

Por sua vez, a aprendizagem e inovação é reflexo da cultura de aprimoramento fomentada, sobretudo, pelo diverso rol de atividades de ensino inerentes à profissão bombeiro militar. A existência de um setor específico para este fim, aliada a tradicional oferta de cursos de formação inicial e continuada, treinamentos e outras formas de capacitação colaboram na obtenção deste score. Além disso, a capacidade de inovação e a formação de comunidades de prática também contribuem para o resultado desta pontuação.

Os somatórios mais baixos, referentes aos critérios de resultados e processos de GC, de certo modo, eram esperados, haja vista o caráter incipiente do tema na organização, sinalizando para a oportunidade de melhoria em decorrência do presente trabalho.

Se por um lado a pontuação global obtida pode transparecer uma fragilidade organizacional no que diz respeito à gestão de seu ativo intelectual, por outro, reflete a realidade da maioria das organizações públicas do Brasil (BATISTA et al., 2014; BATISTA et al., 2015). Mesmo assim, o nível de iniciação também pode ser visto positivamente, sendo um primeiro manifesto institucional na tentativa de melhor gerenciar o seu conhecimento.

Além do grau de maturidade, este processo de autoavaliação também colaborou na identificação de pontos fortes e oportunidades de melhoria em GC na organização, que são sumarizados na subseção seguinte.

Perspectivas em Gestão \& Conhecimento, João Pessoa, v. 11, número especial, p. 35-55, mar. 2021. 


\subsection{Pontos fortes e oportunidades de melhoria da GC no CBMAL}

Os dados aqui reunidos, sistematizados no Apêndice 1, foram obtidos junto aos participantes da oficina de GC realizada junto ao CBMAL. Após as orientações devidas, cada grupo procedeu uma discussão interna entre seus integrantes, levando ao registro dos pontos fortes e oportunidades de melhoria que julgaram pertinentes. Os apontamentos iniciais foram submetidos à análise de conteúdo, realizando-se um processo de categorização em três níveis até o resultado final. Neste percurso, foram mesclados alguns pontos similares e outros foram realocados para um critério de avaliação mais adequado.

Para além dos pontos fortes, que devem ser aproveitados e otimizados para fins de GC, as oportunidades de melhoria evidenciam as lacunas que poderão ser sanadas pela intervenção adequada da GC. Neste sentido, visando a institucionalização da GC da organização, cada um dos critérios avaliados necessita de uma abordagem específica por ocasião da elaboração do futuro PGC do CBMAL, que sucede a esta etapa de diagnóstico, conforme a metodologia do MGCAPB. Neste processo, devem ser considerados os apontamentos obtidos junto ao pessoal envolvido com a temática na organização, conferindo legitimidade às ações gerenciais e otimizando a tomada de decisão.

\section{CONSIDERAÇÕES FINAIS}

A Gestão do Conhecimento se mostra como alternativa viável para as organizações, subsidiando-Ihes ao enfrentamento dos desafios dessa nova era, onde o conhecimento é tido como seu recurso principal. Para o setor público, seu conjunto de práticas e abordagens colabora para o aprimoramento dos processos, produtos e serviços prestados à sociedade, manifestando-se através da inovação e da aprendizagem continuada.

O presente trabalho teve por objetivo diagnosticar o grau de maturidade em Gestão do Conhecimento do Corpo de Bombeiros Militar de Alagoas, identificando pontos fortes e oportunidades de melhoria. Para tanto, recorreu ao Instrumento de Avaliação da GC na Administração Pública, que integra o MGCAPB.

O diagnóstico do grau de maturidade em GC do CBMAL ratificou a hipótese da pesquisa, no que tange ao estágio inicial da GC na corporação, evidenciando uma lacuna de desenvolvimento até o mais elevado nível de maturidade em GC, que corresponde à institucionalização. Ademais, este processo de autoavaliação colaborou na identificação de pontos fortes e oportunidades de melhoria da GC na organização, dando base para a consolidação das demais etapas concernentes à implementação do PGC do CBMAL.

A contribuição acadêmica do presente estudo se atesta pela originalidade da abordagem conferida ao tema em uma organização bombeiro militar, que poderá ser estendida a instituições de natureza similar, nas áreas de defesa e segurança pública do Brasil e do exterior. Trata-se de uma aplicação prática do Modelo de Gestão do Conhecimento para a Administração Pública Brasileira, reafirmando sua viabilidade para esta categoria de instituições e colaborando para o retrato do atual estado do setor público brasileiro em termos de GC.

Para a organização alvo da pesquisa, o CBMAL, contribui sobremaneira ao passo que enaltece o papel do conhecimento enquanto valioso ativo para a instituição, examinando-o sob a ótica dos preceitos da GC como uma vertente moderna de administração. O que se espera, portanto, é uma corporação mais inteligente, que se baseie na aprendizagem para o seu contínuo desenvolvimento, onde o conhecimento seja visto como sua marca principal. Colabora, ainda, de maneira específica, à medida em que se cumpre, na íntegra, a primeira atividade prevista na etapa de diagnóstico do MGCAPB: a autoavaliação.

Perspectivas em Gestão \& Conhecimento, João Pessoa, v. 11, número especial, p. 35-55, mar. 2021. 
Para a sociedade, trás à tona uma oportunidade de melhoria dos serviços prestados pela organização, essenciais para a salvaguarda da vida, do patrimônio e do meio ambiente, garantidos pela constituição e imprescindíveis ao bem-estar social. Tal apontamento se confirma pelo vasto de rol de competências atribuídas à instituição, cujo incremento de qualidade e inovação contínua devem ser resultantes da implementação da GC na instituição.

Como limitações da pesquisa, cabe a ressalva que a aplicação do instrumento em questão se ateve ao pessoal encarregado pela gestão em nível tático e estratégico dos critérios de avaliação propostos pelo MGCAPB. Neste viés, deve-se registrar a importância do envolvimento amplo do efetivo no planejamento das ações decorrentes do presente diagnóstico, contemplando, de uma forma razoável e pertinente, os anseios e ideias das pessoas atingidas pela intervenção, conferindo solidez e validade às decisões tomadas, em um processo de gestão participativa.

Como sugestões de trabalhos futuros, recomenda-se o mapeamento das iniciativas de GC existentes em organizações de natureza similar no Brasil e no exterior, subsidiando o planejamento da GC no âmbito do CBMAL.

\section{REFERÊNCIAS}

AGUNE, Roberto et al. Gestão do Conhecimento e Inovação no Setor Público: Dá pra fazer. São Paulo: Secretaria de Planejamento e Desenvolvimento Regional, 2014. 167 p.

ALAGOAS. Lei Estadual no 7.444, de 28 de dezembro de 2012. Dispõe sobre a organização básica do Corpo de Bombeiros Militar do Estado de Alagoas e dá outras providências. Maceió, AL, 28 dez. 2012.

ALAGOAS. Lei Delegada no 47, de 10 de agosto de 2015. Institui o Modelo de Gestão da Administração Pública Estadual do Poder Executivo e dá outras providências. Maceió, AL, 11 ago. 2015.

ANGELIS, Cristiano Trindade de. Gestão do Conhecimento no setor público: um estudo de caso por meio do método OKA. Revista do Serviço Público, Brasília, v. 62, n. 2, p.137-166, jun. 2011.

ANGELIS, Cristiano Trindade de. A Emergência da Reforma do Estado Brasileiro: a governança compartilhada e o modelo do novo serviço público. Planejamento e Políticas Públicas, Brasília, v. 21, n. 45, p.13-46, dez. 2015.

BATISTA, Fábio Ferreira et al. Gestão do Conhecimento na Administração Pública. Texto para discussão no 1095. Brasília: IPEA, 2005.

BATISTA, Fábio Ferreira et al. Casos reais de implantação do Modelo Gestão do conhecimento para a Administração Pública Brasileira. Texto para discussão no 1941. Brasília: IPEA, 2014.

BATISTA, Fábio Ferreira et al. Casos reais de implantação do Modelo Gestão do Conhecimento para a Administração Pública Brasileira: a experiência do governo de Minas Gerais. Texto para discussão no 2038. Brasília: IPEA, 2015.

BATISTA, Fábio Ferreira. Governo que aprende: Gestão do Conhecimento em Organizações do Executivo Federal. Texto para discussão no 1022. Brasília: IPEA, 2004.

Perspectivas em Gestão \& Conhecimento, João Pessoa, v. 11, número especial, p. 35-55, mar. 2021. 
BATISTA, Fábio Ferreira. Modelo de Gestão do Conhecimento para a Administração Pública Brasileira: Como implementar a Gestão do Conhecimento para produzir resultados em benefício do cidadão. Brasília: Ipea, 2012. 132 p.

BATISTA, Fábio Ferreira. Gestão do Conhecimento na Administração Pública: Resultados da pesquisa IPEA 2014 - grau de externalização e formalização. Texto para discussão no 2066. Brasília: IPEA, 2015.

BATISTA, Fábio Ferreira (Org.). Experiências Internacionais de Implementação da Gestão do Conhecimento no Setor Público. Rio de Janeiro: IPEA, 2016. 178 p.

BRASIL. Constituição (1988). Portal da Legislação do Governo Federal. Brasília, DF, Disponível em: http://www.planalto.gov.br/ccivil 03/constituicao/constituicao.htm. Acesso em: 10 mar. 2019.

BRASIL. Decreto no 8638, de 15 de janeiro de 2016. Institui a Política de Governança Digital no âmbito dos órgãos e das entidades da administração pública federal direta, autárquica e fundacional. Diário Oficial da União. Brasília, DF, 2016.

CARILLO, Francisco Javier. Drivers and processes: Experiences of implementation of Knowledge Management in Public Administration in Mexico. In: BATISTA, Fábio Ferreira (Org.). Experiências Internacionais de Implementação da Gestão do Conhecimento no Setor Público. Rio de Janeiro: IPEA, 2016. p. 97-138.

CAVALCANTE, Pedro. Gestão pública contemporânea: Do movimento gerencialista ao pósNPM. Texto para Discussão № 2319. Brasília: IPEA, 2017.

CORPO DE BOMBEIROS MILITAR DE ALAGOAS (CBMAL). Plano Estratégico 2020-2024. Maceió, AL, 2020.

CORPO DE BOMBEIROS MILITAR DE ALAGOAS (CBMAL). História. 2019. Disponível em: http://www.cbm.al.gov.br/paginas/view/1/historia. Acesso em: 17 mar. 2019.

CORPO DE BOMBEIROS MILITAR DE ALAGOAS (CBMAL). Quartéis. 2019. Disponível em: http://www.cbm.al.gov.br/paginas/quarteis. Acesso em: 17 mar. 2019.

DALKIR, Kimiz. Knowledge management in theory and practice. Oxford: Elsevier, 2005.

FRESNEDA, Paulo Sérgio Vilches; GONÇALVES, Sonia Maria Goulart. A experiência brasileira na formulação de uma proposta de política de gestão do conhecimento para a administração pública federal. Brasília: Câmara dos Deputados, 2007.

IVES, William; TORREY, Ben; GORDON, Cindy. Knowledge Management: An Emerging Discipline with a Long History. Journal Of Knowledge Management, [s.I.], v. 1, n. 4, p.269-274, dez. 1997.

LAIHONEN, Harri; MÄNTYLÄ, Sari. Strategic knowledge management and evolving local government. Journal Of Knowledge Management, [s.I.], v. 22, n. 1, p.219-234, 8 jan. 2018.

Perspectivas em Gestão \& Conhecimento, João Pessoa, v. 11, número especial, p. 35-55, mar. 2021. 
LIRA, Luiz Augusto de Medeiros; LEMOS, Fabio Henrique Guttoski. Administração Pública Gerencial, Gestão do Conhecimento e Comunidades de Prática: estudo de caso no Corpo de Bombeiros Militar de Alagoas. Revista Flammae: Revista Científica do Corpo de Bombeiros Militar de Pernambuco, João Pessoa, v. 3, n. 8, p.97-125, dez. 2017.

LIRA, Luiz Augusto de Medeiros; PINTO, Ibsen Mateus Bittencourt Santana. Gestão do Conhecimento: perspectivas para o Corpo de Bombeiros Militar de Alagoas. In: Simpósio de Engenharia da Produção, 6., 2018, Salvador. Anais [...] Salvador: Even 3, 2018. p. 1 - 10.

MARQUES, Juliano Martins Ramalho et al. The relationship between organizational commitment, knowledge transfer and knowledge management maturity. Journal of Knowledge Management, [s.I.], v. 23, n. 3, p.489-507, 8 abr. 2019.

MASSARO, Maurizio; DUMAY, John; GARLATTI, Andrea. Public sector knowledge management: a structured literature review. Journal of Knowledge Management, [s.I.], v. 19, n. 3, p.530558, 11 maio 2015.

MCADAM, Rodney; REID, Renee. A comparison of public and private sector perceptions and use of knowledge management. Journal of European Industrial Training, [s.l.], v. 24, n. 6, p.317-329, ago. 2000.

PAIXÃO, Ricardo Luís. Gestão do Conhecimento: estudo de casos no setor público. 2004. 142 f. Dissertação (Mestrado) - Curso de Mestrado em Administração, Universidade Federal do Rio de Janeiro, Rio de Janeiro, 2004.

RONDÔNIA (Estado). Decreto no 2260, de 14 de março de 2018. Institui a Política de Gestão do Conhecimento no âmbito da Administração Direta e Indireta do poder Executivo Estadual. Porto Velho, RO, 14 mar. 2018.

SÃO PAULO (Estado). Decreto no 56.963, de 21 de janeiro de 2009. Institui, no âmbito da Administração Pública Estadual, a Política de Gestão do Conhecimento e Inovação e dá providências correlatas. Diário Oficial do Estado. São Paulo, SP, 22 jan. 2009.

SCHLESINGER, Cristina C. Barros et al. Gestão do Conhecimento na Administração Pública. Curitiba: Imap, 2008.

SEPLAG. Resolução no 55, de 27 de julho de 2012. Dispõe sobre a instituição da Política de Gestão do Conhecimento, no âmbito da Administração Direta e Indireta, Autárquica e Fundacional do Poder Executivo Estadual. Belo Horizonte, MG, 27 jul. 2012.

SVEIBY, Karl-erik; SIMONS, Roland. Collaborative climate and effectiveness of knowledge work - an empirical study. Journal Of Knowledge Management, [s.I.], v. 6, n. 5, p.420-433, dez. 2002.

TAKEUCHI, Hirotaka. Knowledge-Based View of Strategy. Universia Business Review, [s.i], v. 10, n. 40, p.68-79, set. 2013.

WIIG, Karl M. Knowledge Management: An Introduction and Perspective. Journal Of Knowledge Management, [s.I.], v. 1, n. 1, p.6-14, mar. 1997.

Perspectivas em Gestão \& Conhecimento, João Pessoa, v. 11, número especial, p. 35-55, mar. 2021. 
WIIG, Karl M. Knowledge management in public administration. Journal of Knowledge Management, [s.l.], v. 6, n. 3, p.224-239, ago. 2002.

Recebido em/Received: 06/02/2021 | Aprovado em/Approved: 22/02/2021 


\section{APÊNDICE I - Pontos fortes e oportunidades de melhoria da GC no CBMAL}

\begin{tabular}{|c|c|c|}
\hline Critério & Pontos fortes & Oportunidades de melhoria \\
\hline $\begin{array}{c}\text { Liderança } \\
\text { em GC }\end{array}$ & $\begin{array}{l}\text { - Existência de líderes nos diversos níveis e } \\
\text { setores dotados de competências favoráveis à } \\
\text { GC. } \\
\text { - Reconhecimento da importância do } \\
\text { planejamento estratégico para a instituição. } \\
\text { - Interesse institucional no fomento ao } \\
\text { conhecimento. } \\
\text { - Disponibilidade à gestão participativa. } \\
\text { - Disponibilidade financeira-orçamentária para } \\
\text { investimentos em GC. }\end{array}$ & $\begin{array}{l}\text { - Inclusão da GC dentre os objetivos } \\
\text { estratégicos da instituição. } \\
\text { - Estabelecimento de parcerias e } \\
\text { captação de recursos para fins de GC. } \\
\text { - Iniciativas de fomento ao trabalho } \\
\text { colaborativo, ao compartilhamento } \\
\text { do conhecimento e à inovação. } \\
\text { - Direcionamento das pessoas, } \\
\text { otimizando esforços para fins } \\
\text { específicos. }\end{array}$ \\
\hline Processo & $\begin{array}{l}\text { - Documentação dos atos administrativos da } \\
\text { corporação. } \\
\text { - Comunicação e publicidade de informações } \\
\text { institucionais em BGO. } \\
\text { - Implantação da gestão da qualidade em } \\
\text { andamento na organização. } \\
\text { - Atualização continuada da dinâmica dos } \\
\text { processos de trabalho. } \\
\text { - Interação entre os setores da organização. } \\
\text { - Iniciação da padronização de procedimentos } \\
\text { em alguns setores. }\end{array}$ & $\begin{array}{l}\text { - Consolidação da padronização de } \\
\text { procedimentos administrativos e } \\
\text { operacionais. } \\
\text { - Aprimoramento da gestão de } \\
\text { processos na organização. } \\
\text { - Compartilhamento das melhores } \\
\text { práticas na gestão processual. } \\
\text { - Monitoramento e supervisão da } \\
\text { gestão da qualidade. } \\
\text { - Descentralização da gestão. }\end{array}$ \\
\hline Pessoas & $\begin{array}{l}\text { - Existência de pessoal qualificado em meio aos } \\
\text { diversos setores da instituição. } \\
\text { - Disponibilidade de pessoal para a produção e } \\
\text { compartilhamento de conhecimento. } \\
\text { - Protagonismo das CTEPs como referências em } \\
\text { GC na corporação. } \\
\text { - Capacitação continuada dos integrantes das } \\
\text { CTEPs. } \\
\text { - Trabalho colaborativo em alguns setores. } \\
\text { - Divisão de atribuições por afinidade e } \\
\text { competência em alguns setores. }\end{array}$ & $\begin{array}{l}\text { - Implantação da Gestão por } \\
\text { - Otimizaçãa do emprego do pessoal } \\
\text { disponível na organização. } \\
\text { - Capacitação específica, em alto nível, } \\
\text { para o exercício das funções. } \\
\text { - Implantação de Comunidades de } \\
\text { Prática em novas áreas de } \\
\text { conhecimento, inclusive } \\
\text { administrativas. } \\
\text { - Criação de processos formais de } \\
\text { mentoring, coaching e tutoria. } \\
\text { - Implantação do banco de } \\
\text { competências. } \\
\text { - Captação e compartilhamento dos } \\
\text { conhecimentos obtidos em } \\
\text { capacitações externas. } \\
\text { - Aprimoramento da comunicação } \\
\text { interna entre pessoas e setores da } \\
\text { organização. }\end{array}$ \\
\hline Tecnologia & $\begin{array}{l}\text { - Portfólio de sistemas informatizados do } \\
\text { CBMAL, produzidos pela própria corporação e } \\
\text { com potencial de aplicabilidade para fins de } \\
\text { GC. } \\
\text { - Disponibilidade de sistema eletrônico para a } \\
\text { gestão de processos e documentos. } \\
\text { - Disponibilidade de sistema de gestão de } \\
\text { projetos e tarefas. } \\
\text { - Disponibilidade de um AVA. } \\
\text { - Disponibilidade de um banco de dados em }\end{array}$ & $\begin{array}{l}\text { - Aprimoramento da infraestrutura de } \\
\text { tecnologia da informação. } \\
\text { - Tratamento e análise dos dados } \\
\text { disponíveis nos sistemas para } \\
\text { produção de informação e } \\
\text { conhecimento. } \\
\text { - Aperfeiçoamento contínuo dos } \\
\text { sistemas informatizados. }\end{array}$ \\
\hline
\end{tabular}

Perspectivas em Gestão \& Conhecimento, João Pessoa, v. 11, número especial, p. 35-55, mar. 2021. 


\begin{tabular}{|l|l|l|}
\hline & $\begin{array}{l}\text { várias áreas da organização. } \\
\text { - Disponibilidade de computadores em todos os } \\
\text { setores da organização. }\end{array}$ & \\
\hline
\end{tabular}

(Continua)

\begin{tabular}{|c|c|c|}
\hline Critério & Pontos fortes & Oportunidades de melhoria \\
\hline $\begin{array}{c}\text { Processos de } \\
\text { GC }\end{array}$ & $\begin{array}{l}\text { - Atuação da CTEPs no âmbito da instituição. } \\
\text { - Realização de estudos, instruções e } \\
\text { treinamentos. } \\
\text { - Atualização dos projetos pedagógicos e } \\
\text { formatação dos cursos internos. } \\
\text { - Uso da Educação a Distância (EAD). } \\
\text { - Participação de oficiais do CBMAL no Comitê } \\
\text { Nacional de Gestão do Conhecimento e } \\
\text { Inovação da LIGABOM. }\end{array}$ & $\begin{array}{l}\text { - Consolidação da doutrina de emprego } \\
\text { institucional. } \\
\text { - Compartilhamento e aplicação dos } \\
\text { conhecimentos produzidos no âmbito } \\
\text { da instituição. } \\
\text { - Aproveitamento do conhecimento } \\
\text { disponível em corporações coirmãs } \\
\text { por meio do benchmarking. } \\
\text { - Captação do conhecimento tácito dos } \\
\text { bombeiros militares. } \\
\text { - Mapeamento do conhecimento } \\
\text { disponível na organização. } \\
\text { - Adoção de medidas de incentivo às } \\
\text { melhores práticas. } \\
\text { - Realização de estudos de caso para } \\
\text { fins de aprendizagem organizacional. } \\
\text { - Otimização do uso da EAD, } \\
\text { desenvolvendo novas possibilidades } \\
\text { pedagógicas. } \\
\text { - Reformulação das normas de ensino, } \\
\text { visando o uso do melhor } \\
\text { conhecimento disponível nos cursos } \\
\text { da corporação. }\end{array}$ \\
\hline $\begin{array}{l}\text { Aprendizagem } \\
\text { e inovação }\end{array}$ & $\begin{array}{l}\text { - Potencial de inovação, aprendizagem e } \\
\text { adaptação às mudanças. } \\
\text { - Oferta contínua de cursos do sistema de } \\
\text { ensino militar. } \\
\text { - Possibilidade de criação de comissões para a } \\
\text { solução de problemas específicos. } \\
\text { - Autonomia e receptividade emanada pelos } \\
\text { superiores. }\end{array}$ & $\begin{array}{l}\text { - Criação de equipes multidisciplinares } \\
\text { para a solução de problemas. } \\
\text { - Adoção de medidas de estímulo e } \\
\text { apoio à aprendizagem e inovação. } \\
\text { - Alinhamento da aprendizagem e } \\
\text { inovação aos objetivos institucionais. }\end{array}$ \\
\hline $\begin{array}{c}\text { Resultados em } \\
\text { GC }\end{array}$ & $\begin{array}{l}\text { - Práticas isoladas, em alguns setores, com } \\
\text { vistas à aprendizagem, melhoria de } \\
\text { desempenho e inovação. } \\
\text { - Possibilidades administrativas advindas da } \\
\text { legislação. } \\
\text { - Credibilidade institucional frente ao público } \\
\text { externo. } \\
\text { - Oportunidade de intervenção da GC na } \\
\text { corporação. }\end{array}$ & $\begin{array}{l}\text { - Implementação de indicadores de } \\
\text { desempenho para mensuração de } \\
\text { resultados. } \\
\text { - Implementação da GC e utilização de } \\
\text { suas diversas práticas e ferramentas. } \\
\text { - Padronização de procedimentos } \\
\text { baseada no melhor conhecimento } \\
\text { disponível. }\end{array}$ \\
\hline
\end{tabular}

Fonte: Elaborado pelo autor.

Perspectivas em Gestão \& Conhecimento, João Pessoa, v. 11, número especial, p. 35-55, mar. 2021. 
ANEXO I - Instrumento para Avaliação da GC - Folhas de Pontuação Individual

\begin{tabular}{|c|c|c|}
\hline \multicolumn{3}{|c|}{ Critério 1 - Liderança em GC } \\
\hline Item & Descrição & Pontuação \\
\hline 1 & $\begin{array}{l}\text { A organização compartilha o conhecimento, a visão e a estratégia de GC } \\
\text { fortemente alinhados com visão, missão e objetivos estratégicos da organização. }\end{array}$ & \\
\hline 2 & $\begin{array}{l}\text { Arranjos organizacionais foram implantados para formalizar as iniciativas de GC } \\
\text { (exemplos: uma unidade central de coordenação da gestão da } \\
\text { informação/conhecimento; gestor chefe de gestão da } \\
\text { informação/conhecimento; equipes de melhoria da qualidade; COPs; e redes de } \\
\text { conhecimento). }\end{array}$ & \\
\hline 3 & Recursos financeiros são alocados nas iniciativas de GC. & \\
\hline 4 & $\begin{array}{l}\text { A organização tem uma política de proteção da informação e do conhecimento } \\
\text { (exemplos: proteção da propriedade intelectual, segurança da informação e do } \\
\text { conhecimento e política de acesso, integridade, autenticidade e sigilo das } \\
\text { informações). }\end{array}$ & \\
\hline 5 & $\begin{array}{l}\text { A alta administração e as chefias intermediárias servem de modelo ao colocar em } \\
\text { prática os valores de compartilhamento do conhecimento e de trabalho } \\
\text { colaborativo. Elas passam mais tempo disseminando informação para suas } \\
\text { equipes e facilitando o fluxo horizontal de informação entre suas equipes e } \\
\text { equipes de outros departamentos/divisões/unidades. }\end{array}$ & \\
\hline 6 & $\begin{array}{l}\text { A alta administração e as chefias intermediárias promovem, reconhecem e } \\
\text { recompensam a melhoria do desempenho, o aprendizado individual e } \\
\text { organizacional, o compartilhamento de conhecimento e a criação do } \\
\text { conhecimento e inovação. }\end{array}$ & \\
\hline \multicolumn{2}{|r|}{ Subtotal 1} & \\
\hline
\end{tabular}

\begin{tabular}{|c|c|c|}
\hline \multicolumn{3}{|c|}{ Critério 2 - Processo } \\
\hline Item & $\begin{array}{ll}\text { Descrição } \\
\end{array}$ & Pontuação \\
\hline 7 & $\begin{array}{l}\text { A organização define suas competências essenciais (capacidades importantes } \\
\text { do ponto de vista estratégico que concede à organização vantagem } \\
\text { comparativa) e as alinha à sua missão e aos objetivos da organização. }\end{array}$ & \\
\hline 8 & $\begin{array}{l}\text { A organização modela seus sistemas de trabalho e processos de apoio e } \\
\text { finalísticos chave para agregar ("ao invés de criar") valor ao cidadão-usuário e } \\
\text { alcançar alto desempenho institucional. }\end{array}$ & \\
\hline 9 & $\begin{array}{l}\text { Na modelagem de processos são contemplados os seguintes fatores: novas } \\
\text { tecnologias, compartilhamento de conhecimento na organização, flexibilidade, } \\
\text { eficiência, eficácia e efetividade social. }\end{array}$ & \\
\hline 10 & $\begin{array}{l}\text { A organização tem um sistema próprio para gerenciar situações de crise ou } \\
\text { eventos imprevistos que assegura a continuidade das operações, prevenção e } \\
\text { recuperação. }\end{array}$ & \\
\hline 11 & $\begin{array}{l}\text { A organização implementa e gerencia os processos de apoio e finalísticos chave } \\
\text { para assegurar o atendimento dos requisitos do cidadão-usuário e a } \\
\text { manutenção dos resultados da organização. }\end{array}$ & \\
\hline 12 & $\begin{array}{l}\text { A organização avalia e melhora continuamente seus processos de apoio e } \\
\text { finalísticos para alcançar um melhor desempenho, reduzir a variação, melhorar } \\
\text { produtos e serviços públicos e para manter-se atualizada com as práticas de } \\
\text { excelência em gestão. }\end{array}$ & \\
\hline \multicolumn{2}{|r|}{ Subtotal 2} & \\
\hline
\end{tabular}

Fonte: APO (2009) apud Batista (2012)

Perspectivas em Gestão \& Conhecimento, João Pessoa, v. 11, número especial, p. 35-55, mar. 2021. 


\begin{tabular}{|c|c|c|}
\hline \multicolumn{3}{|c|}{ Critério 3 - Pessoas } \\
\hline Item & Descrição & Pontuação \\
\hline 13 & $\begin{array}{l}\text { Os programas de educação e capacitação, assim como os de desenvolvimento de } \\
\text { carreiras, ampliam o conhecimento, as habilidades e as capacidades do servidor } \\
\text { público, servem de apoio para o alcance dos objetivos da organização e } \\
\text { contribuem para o alto desempenho institucional. }\end{array}$ & \\
\hline 14 & $\begin{array}{l}\text { A organização dissemina de maneira sistemática informações sobre os } \\
\text { benefícios, a política, a estratégia, o modelo, o plano e as ferramentas de GC } \\
\text { para novos funcionários/servidores da organização. }\end{array}$ & \\
\hline 15 & A organização tem processos formais de mentoring, coaching e tutoria. & \\
\hline 16 & A organização conta com banco de competências dos seus servidores públicos. & \\
\hline 17 & $\begin{array}{l}\text { A colaboração e o compartilhamento do conhecimento são ativamente } \\
\text { reconhecidos e recompensados/corrigidos. }\end{array}$ & \\
\hline 18 & $\begin{array}{l}\text { A organização do trabalho contempla a formação de pequenas equipes/grupos } \\
\text { (exemplos: grupos de trabalho, comissões, círculos de qualidade, equipes de } \\
\text { melhoria de processos de trabalho, equipes interfuncionais, equipes } \\
\text { interdepartamentais, COPs) e a estrutura por processos para enfrentar as } \\
\text { preocupações e os problemas no local de trabalho. }\end{array}$ & \\
\hline \multicolumn{2}{|r|}{ Subtotal 3} & \\
\hline
\end{tabular}

Fonte: APO (2009) apud Batista (2012)

\begin{tabular}{|c|l|c|}
\hline \multicolumn{2}{|c|}{ Critério 4 - Tecnologia } \\
\hline Item & \multicolumn{1}{|c|}{ Descrição } & Pontuação \\
\hline 19 & $\begin{array}{l}\text { A alta administração implantou uma infraestrutura de TI (exemplos: internet, } \\
\text { intranet e sítio na Rede Mundial de Computadores (web) e dotou a organização } \\
\text { com a estrutura necessária para facilitar a efetiva GC. }\end{array}$ & \\
\hline 20 & A infraestrutura de TI está alinhada à estratégia de GC da organização. & \\
\hline 21 & Todas as pessoas da organização têm acesso a computador & \\
\hline 22 & Todas as pessoas têm acesso à internet/intranet e a um endereço de e-mail. & \\
\hline 23 & $\begin{array}{l}\text { As informações disponíveis no sítio da web/intranet são atualizadas } \\
\text { regularmente. }\end{array}$ & $\begin{array}{l}\text { A intranet (ou uma rede similar) é usada como a principal fonte de comunicação } \\
\text { em toda a organização como apoio à transferência de conhecimento e ao } \\
\text { compartilhamento de informação. }\end{array}$ \\
\hline & \multicolumn{1}{|c|}{ Subtotal 4 } \\
\hline
\end{tabular}

Fonte: APO (2009) apud Batista (2012)

\begin{tabular}{|c|l|c|}
\hline \multicolumn{3}{|c|}{ Critério 5 - Processos de conhecimento } \\
\hline Item & \multicolumn{1}{|c|}{ Descrição } & \multicolumn{1}{|c|}{ Pontuação } \\
\hline 25 & $\begin{array}{l}\text { A organização tem processos sistemáticos de identificação, criação, } \\
\text { armazenamento, compartilhamento e utilização do conhecimento. }\end{array}$ & \\
\hline 26 & $\begin{array}{l}\text { A organização conta com um mapa de conhecimento e distribui os } \\
\text { ativos ou recursos de conhecimento por toda a organização. }\end{array}$ & \\
\hline 27 & $\begin{array}{l}\text { O conhecimento adquirido após a execução de tarefas e a conclusão de } \\
\text { projetos é registrado e compartilhado. }\end{array}$ & \\
\hline 28 & $\begin{array}{l}\text { O conhecimento essencial de servidores públicos que estão saindo da } \\
\text { organização é retido. }\end{array}$ & \\
\hline 29 & $\begin{array}{l}\text { A organização compartilha as melhores práticas e lições aprendidas por } \\
\text { toda a organização para que não haja um constante "reinventar da } \\
\text { roda" e retrabalho. }\end{array}$ & \\
\hline 30 & $\begin{array}{l}\text { As atividades de benchmarking são realizadas dentro e fora da } \\
\text { organização, os resultados são usados para melhorar o desempenho } \\
\text { organizacional e criar novo conhecimento. }\end{array}$ & \\
\hline & \multicolumn{1}{c|}{ Subtotal 5 } \\
\hline
\end{tabular}

Fonte: APO (2009) apud Batista (2012)

Perspectivas em Gestão \& Conhecimento, João Pessoa, v. 11, número especial, p. 35-55, mar. 2021. 


\begin{tabular}{|c|l|c|}
\hline \multicolumn{2}{|c|}{ Critério 6 - Aprendizagem e inovação } & Pontuação \\
\hline Item & \multicolumn{1}{|c|}{ Descrição } & \multicolumn{1}{|c|}{} \\
\hline 31 & $\begin{array}{l}\text { A organização articula e reforça continuamente como valores a } \\
\text { aprendizagem e a inovação. }\end{array}$ & $\begin{array}{l}\text { A organização considera a atitude de assumir riscos ou o fato de cometer } \\
\text { erros como oportunidades de aprendizagem desde que isso não ocorra } \\
\text { repetidamente. }\end{array}$ \\
\hline 32 & $\begin{array}{l}\text { Equipes interfuncionais são formadas para resolver problemas ou lidar } \\
\text { com situações preocupantes que ocorrem em diferentes unidades } \\
\text { gerenciais da organização. }\end{array}$ & $\begin{array}{l}\text { As pessoas sentem que recebem autonomia dos seus superiores } \\
\text { hierárquicos e que suas ideias e contribuições são geralmente valorizadas } \\
\text { pela organização. }\end{array}$ \\
\hline 33 & $\begin{array}{l}\text { As chefias intermediárias estão dispostas a usar novas ferramentas e } \\
\text { métodos. }\end{array}$ & $\begin{array}{l}\text { As pessoas são incentivadas a trabalhar junto com outros e a compartilhar } \\
\text { informação. }\end{array}$ \\
\hline 35 & \multicolumn{1}{c}{ Subtotal 6 } \\
\hline 36 & \multicolumn{2}{|l|}{ Fonte: APO (2009) apud Batista (2012) } \\
\hline
\end{tabular}

Fonte: APO (2009) apud Batista (2012)

\begin{tabular}{|c|l|c|}
\hline \multicolumn{2}{|c|}{ Critério 7 - Resultados da GC } \\
\hline Item & \multicolumn{1}{|c|}{ Descrição } & Pontuação \\
\hline 37 & $\begin{array}{l}\text { A organização tem um histórico de sucesso na implementação da GC e de outras } \\
\text { iniciativas de mudança que pode ser comprovado com resultados de indicadores } \\
\text { de desempenho. }\end{array}$ & \\
\hline 38 & $\begin{array}{l}\text { São utilizados indicadores para avaliar o impacto das contribuições e das } \\
\text { iniciativas de GC nos resultados da organização. }\end{array}$ & \\
\hline 39 & $\begin{array}{l}\text { A organização melhorou - graças às contribuições e às iniciativas da GC - os } \\
\text { resultados relativos aos indicadores de qualidade dos produtos e serviços. }\end{array}$ & \\
\hline 40 & $\begin{array}{l}\text { A organização melhorou - graças às contribuições e às iniciativas de GC - os } \\
\text { resultados relativos aos indicadores de eficiência. }\end{array}$ & $\begin{array}{l}\text { A organização melhorou - graças às contribuições e às iniciativas de GC - os } \\
\text { resultados relativos aos indicadores de efetividade social. }\end{array}$ \\
\hline 41 & $\begin{array}{l}\text { A organização melhorou - graças às contribuições e às iniciativas de GC - os } \\
\text { resultados dos indicadores de legalidade, impessoalidade, publicidade, } \\
\text { moralidade e desenvolvimento. }\end{array}$ \\
\hline & \multicolumn{1}{c}{ Subtotal 7 } \\
\hline
\end{tabular}

Fonte: APO (2009) apud Batista (2012)

Perspectivas em Gestão \& Conhecimento, João Pessoa, v. 11, número especial, p. 35-55, mar. 2021. 